\title{
DEMOGRAPHIC SITUATION IN URBAN AREAS OF REPUBLIC OF BULGARIA IN THE LAST 25 YEARS
}

DOI: http://dx.doi.org/10.18509/GBP.2015.27

UDC: $314.911 .375(497.2), 1990-2015 “ 6$

\author{
Assoc. Prof. Dr. Kliment Naydenov \\ Assoc. Prof. Dr. Toni Traykov \\ Sofia University “St. Kliment Ohridski”, Bulgaria
}

\begin{abstract}
Dynamics in the development of demographic processes and changes in the structures of the population in recent decades have influenced the main systems of society: economic, educational, health insurance and social protection system. Demographic situation in Bulgarian cities deteriorated over the past 25 years. This is especially characteristic of small towns whose population decreased by high rates. Migration of young people from these settlements leads to reduced economic potential and worsening demographic potential. Generally have the same fate and cities in our country.
\end{abstract}

Keywords: demographic crisis, the demographic transition, urban population

\section{INTRODUCTION}

The demographic crisis is a violation of the natural process of reproduction of the population, leading to regressive changes of its structural characteristics.[1] During the 80 years of the $20^{\text {th }}$ century have started negative changes in fertility and mortality of the population this is precondition for modern demographic crisis in Bulgaria. Trends and changes related to the demographic crisis show features the time of display in urban and rural population of Bulgaria. The trends and changes of the display in urban and rural population of Bulgaria is related to the demographic crisis. Differences in their speed and expressiveness are depending on the action of various socio-economic factors affecting the normal course of running the demographic transition in Bulgarian towns and villages in the second half of the 20th century. In this direction some influence have sociopsychological factors, the effect of which is increasing during periods of socio-economic change, financial and economic crises. During the last decades the leaning new attitudes and value orientation are mainly focused seeking ways to better personal realization of young people. In those who are parents changes in the initial reproductive plans are associated both with the ambition to own realization and to ensure a better future for children. Under the existing in our standard of living they see such possibilities mainly by limiting the number of children in the family. The demographic situation of cities in Bulgaria is the result of the action of influences and factors on the one hand are typical of the country, on the other hand are characteristic of demographic developments in European countries, and a third are determined by the specific historical and cultural, socio-economic and demographic development of the cities themselves.[4] The demographic development of the urban population influenced the demographic processes, which are common to both cities in developed countries and cities in countries in transition. These are the processes associated with high levels of mortality and emigration and reduced marriage and birth rates. Serious impact on these processes has sex and age, ethnic, religious and educational structure of the population. They affect the formation of 
human resources in cities, both in quantitative and qualitative terms. Negative trends in demographic processes in Bulgarian cities in recent decades and result from changes in the number and structure of the population strongly influence the main systems of the society in the city: economy, education, health insurance and social protection system. The current demographic situation in the country is characterized by a continuing decline and aging population, declining birth rates and continued high level of mortality.

Historically there are several periods in the urbanization process in Bulgaria. Overall, from 1887 to 1934 , the share of urban population is growing slightly, while the rural population has a negative migration increase, but high natural increase. Therefore, the proportion of urban population between 1887 and 1934 increased from $18.8 \%$ to $21.4 \%$. For the period 1934-1946 the urban population increased from 1303 thousand people to 1735 thousand people, its share increased from 21.4 to $25.7 \%$. In the period 1946-1956 urban population of Bulgaria increased from 1735 thousand people to 2556 thousand people, or 821 thousand people. At the end of the 40s of last century, it varies around 15$16 \%$, and in the early 50s - between 20 and 30\%. For the years 1956-65 observed a considerable growth of the urban population - from 2556 thousand people to 3823 thousand people. During these years urbanization processes evolve rapidly, as observed number of features and weaknesses associated with the state planned economy. Between the next two censuses - 1965-1975, the urban population keep growing. During the mentioned period the urban population in the country increased from 3823 thousand people to 5061 thousand people, or about 1240 thousand people. During the 50s of the previous century political changes relating to the imposition of the socialistic model of social and economic development in Bulgaria are the main reason for accelerated redistribution of population. Mandatory and universal cooperation in the villages and the country's industrialization led to a rapid increase in urban population at the expense of reduction of the rural population. Changes in the urban structure of the population in this period a strong influence caused mass migrations from the countryside to cities, village's accession as neighborhoods of cities, and the diverse development of reproduction in urban and rural population. In this period, mass migration from the countryside to cities are caused by changes in the urban structure of the population also villages accession as neighborhoods of cities and the diverse development of reproduction in urban and rural population. Influence in this direction is also changes in the status of the settlements. For example, in the period between the censuses in 1956 and 1975 - 103 villages are declared cities without having all the necessary prerequisites for this. Other 220 villages were joined as city neighborhoods. Between 1965 and 1975 cities in the country increased from 137 to 214 . Therefore, the proportion of urban population increased from $46.5 \%$ to $58 \%$. The period 1975-1985 was characterized by the fact that in early 1980s Bulgaria entered the third phase of the urbanization process. The urban population keep growing, but between these two censuses the increase is about 2 times less compared to the period 1965-75 (from 5061 thousand people to 5800 thousand, or about 700 thousand people ). In the next period, between the censuses of 1985 and 1992 appeared some new features in the urbanization process. For the first time the absolute number of urban population shows a decline (from 5800 thousand people in 1985 to 5705 thousand people in 1992). 
This period is characterized by a reducing birth rate among the urban population, continuation of aging and therefore increasing mortality rate. Despite of its unfavorable demographic development the urban population has a minimal positive value. In the early years of the social-economic transition of the country the migratory flows from village to cities (rural-urban movements) get weaker, while new trends appear - for example the unemployment and the cost of living in the cities keep increasing. However, the reverse migration has risen. These urban-rural movements include in general retired people and former residents of the respective villages. The country's urbanization was also affected by the emigration, which started in the spring of 1989 . For this reason, the urban population decreases absolutely, but its share is amended in a positive way - by $64.8 \%$ (1985) to $68.0 \%$ (1992). Moreover, in the period 1985-1992 has decreased the average number of inhabitants of a city. Since the beginning of the 90 s of last century urbanization occurs in transition to a market economy. Between the last two censuses (1992-2001) the urban population decreased from 5705 thousand people to 5501 thousand, but its relative share increased from $67.2 \%$ to $68.4 \%$. Since 2001 , the urban population decreases absolutely, and in 2007 was 5403 thousand people. However, due to the rapid decline of the rural population, the proportion of urban population increased to $70.7 \%$. Positive trends in 2013 include reducing the level of mortality and infant mortality and increasing life expectancy of the population. At the end of 2013 the urban population is 5,291,675, or $73.0 \%$, and the rural population $-1,954,002$, or $27.0 \%$ of the population.

At the end of 2014 the cities in the country are 257 . The distribution of population in urban areas at the end of the year is a result of its natural and mechanical movement, but also by administrative changes in the urban structure of the country. Currently the country has seven cities with a population over 100,000 people in which live $34.3 \%$ of the population of the Republic of Bulgaria.

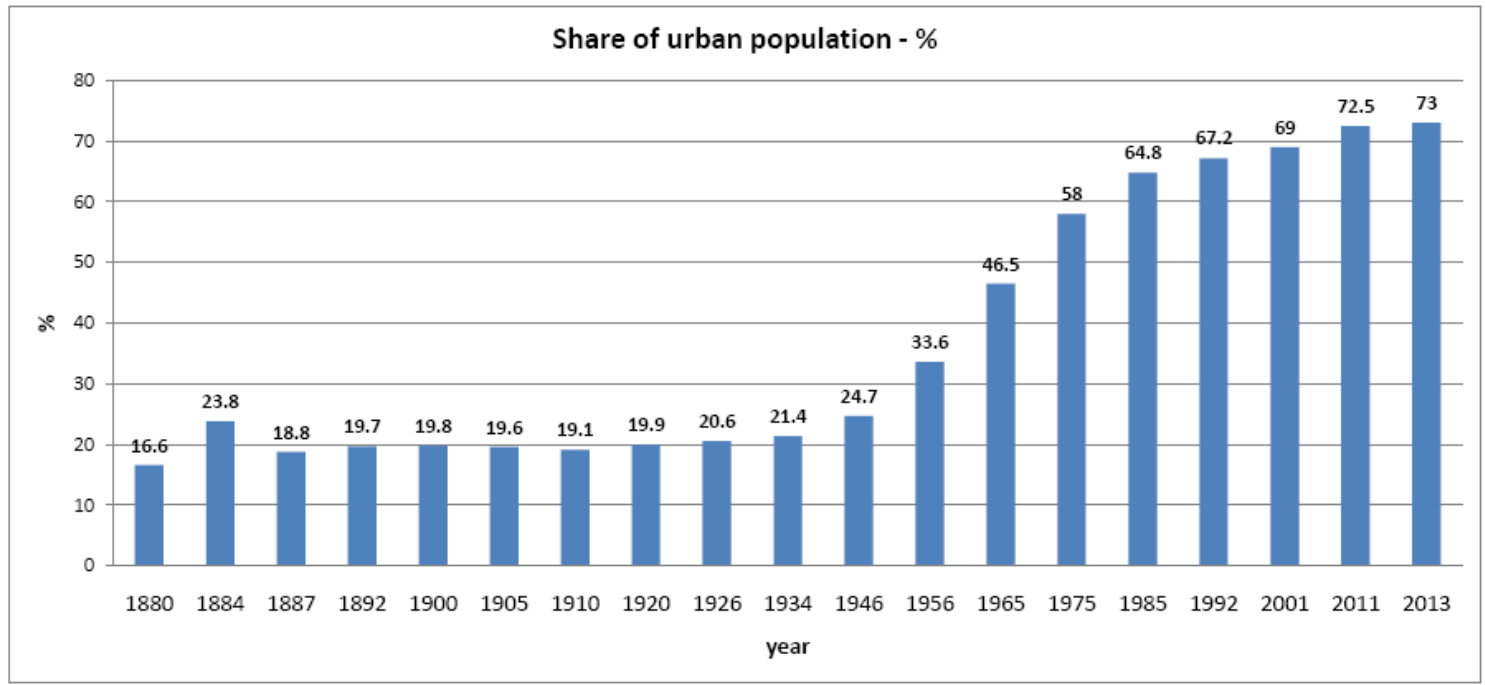

Figure 1, Source: National Statistical Institute

Impact on the gender structure of the urban population has processes associated with the natural movement of population (births and deaths), the mechanical movement of the 
population (emigration and immigration), life expectancy and others. Throughout the study period women prevail over men. The main reason for the higher number and proportion female population is a higher mortality and a lower life expectancy in men. On average, this leads to the accumulation of prevalence of female population in older age groups. Sexually-age pyramids clearly show the future aging of the urban population, the aging of the rural population at the time and the future deterioration of the age composition of the population in the country, which will reduce the labor potential.

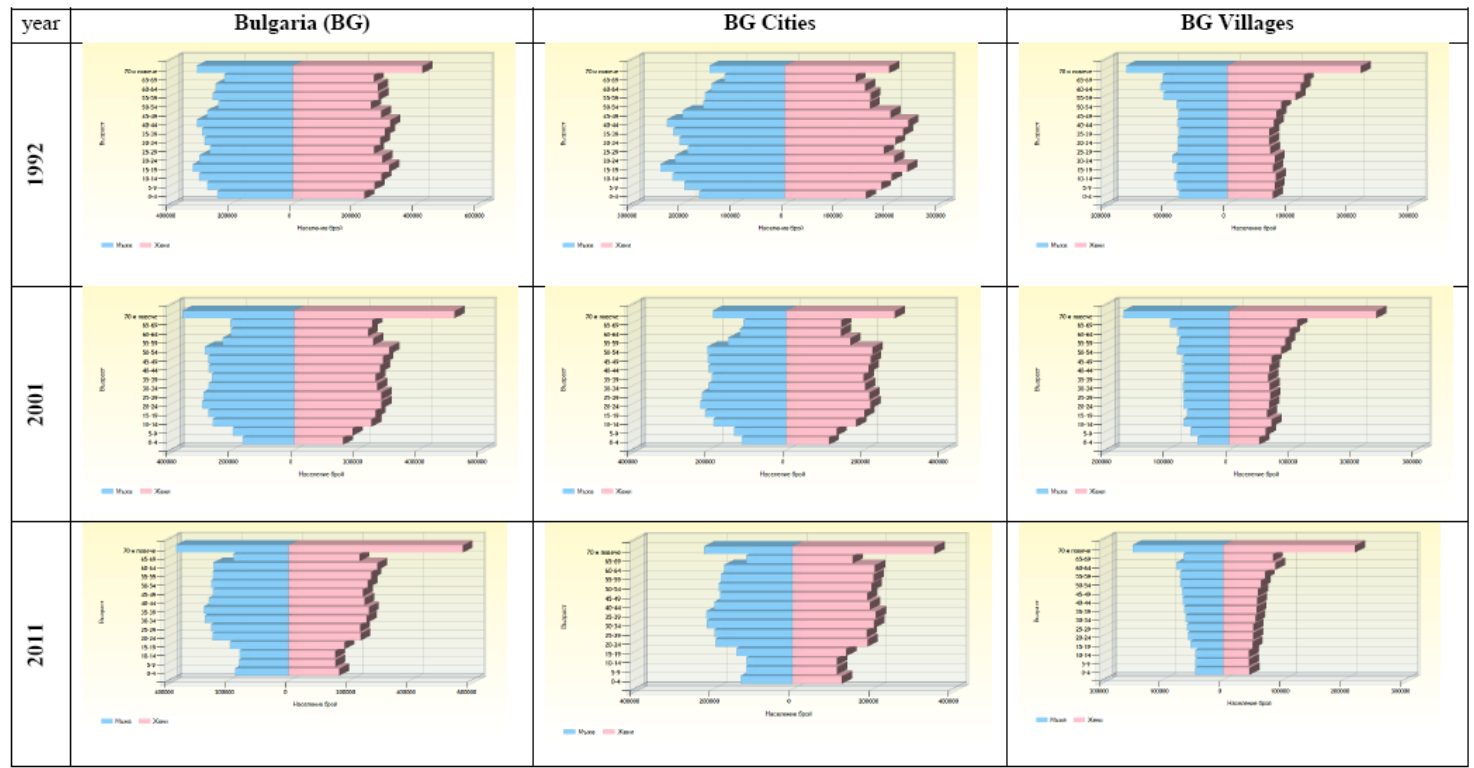

Figure 2, Source: National Statistical Institute

At the end of 2013 the total age dependency ratio is $50.0 \%$, or to any person in dependent age (under 15 and over 65 years). This ratio is more favorable in urban areas $-44.8 \%$, than in rural areas $-65.8 \%$. The population aging leads to an increase in the median age, from 40.4 years in 2001 to 41.2 years in 2005 and reached 43.0 years at the end of 2013. The aging process is manifested in the villages and cities; the average age of the population in the cities is 41.9 years, while in rural areas -45.9 years.

Registered legal marriages in 2013 were 21943 - with 776 more than the previous year. $77.7 \%$ of all registered marriages $(17,047)$ are among the urban population; while in the villages were concluded 4896 marriage. The number of divorces in 2013 was 10,908 with 1,039 less than those in $2012.83 .0 \%$ of all ended marriages refer to the urban population. 


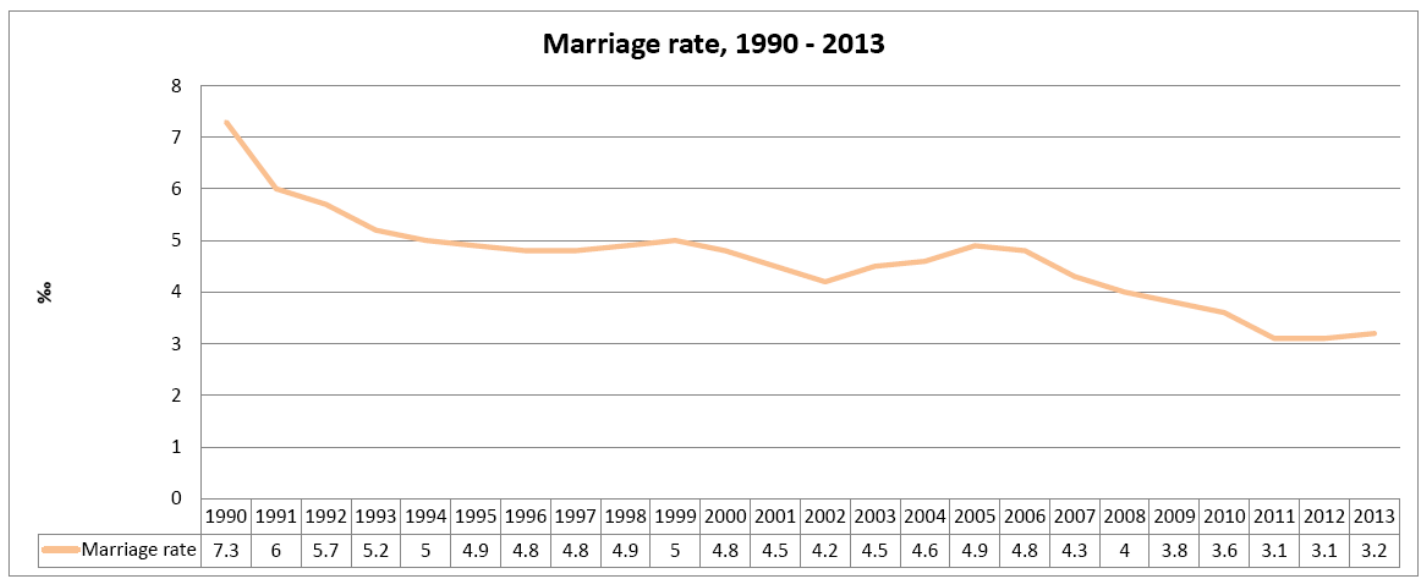

Figure 3, Source: National Statistical Institute

In 2013 live births in towns and villages are respectively 49526 and 17052 children. The birth rate in cities is $9.3 \%$, and in villages $-8.7 \%$. In 2012, these ratios were accordingly 9.7 and $8.8 \%$. Overall, it can be noted that the birth rate is insufficient throughout the study period.

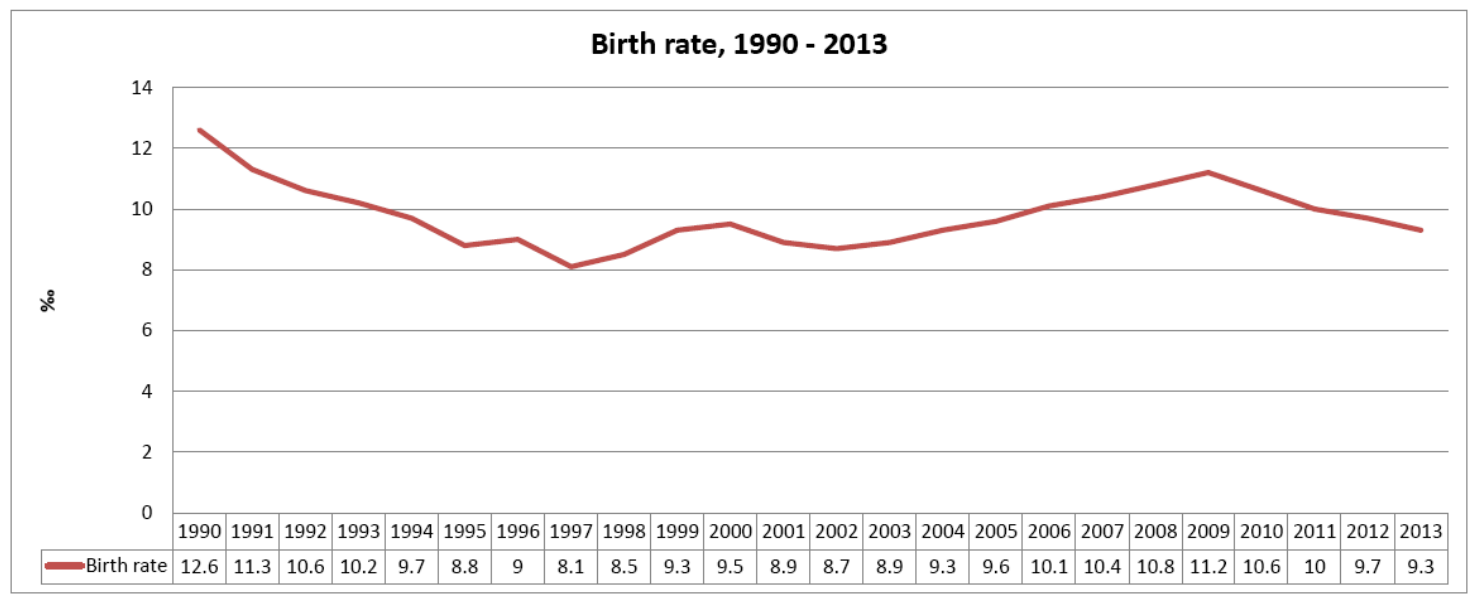

Figure 4, Source: National Statistical Institute

There are marked differences in mortality among the urban and rural population. The mortality rate is a higher in rural areas $(20.5 \%$ ) than in cities (12.1 \%o). However, mortality in the cities remains very high throughout the study period. The average life expectancy for the total population of the country, calculated for the period 2011 - 2013, was 74.5 years. The average life expectancy for men is 71.0 years, while for women is 7 years higher -78.0 years. The average life expectancy was 2.7 years higher for the urban population ( 75.3 years) than the rural population ( 72.6 years). 


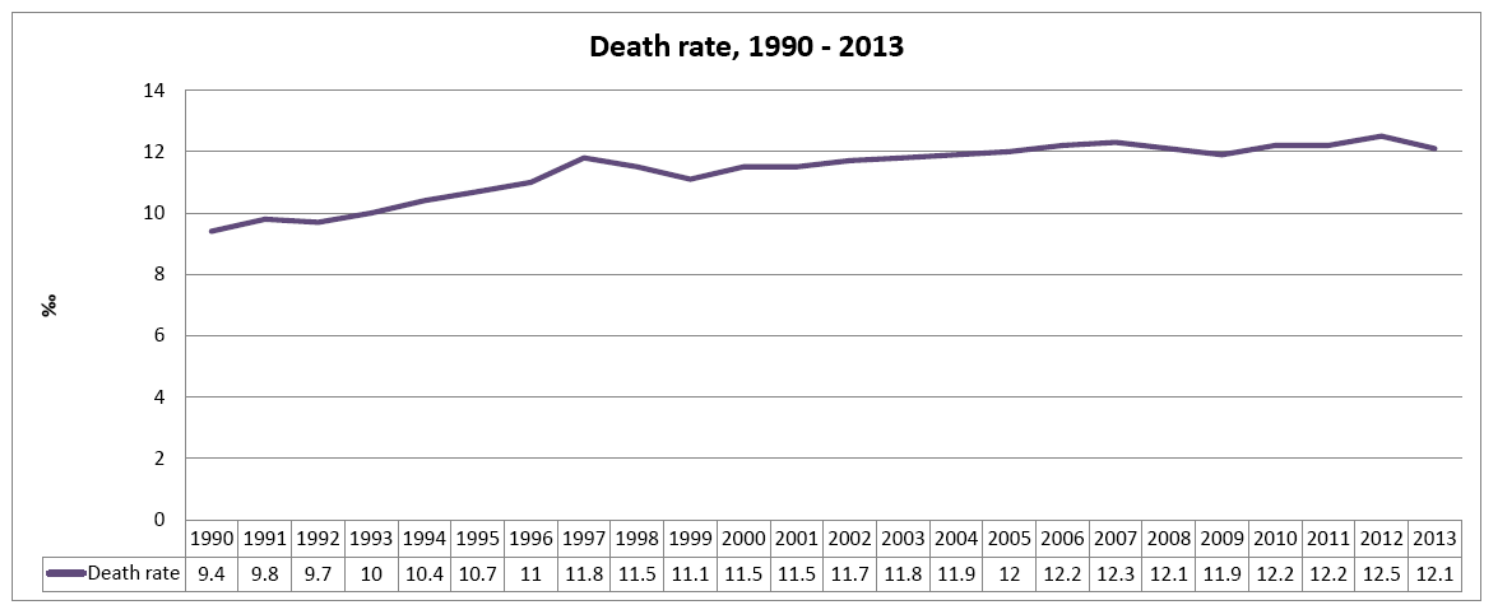

Figure 5, Source: National Statistical Institute

Infant mortality is an indicator reflecting the level of medical care and the standard of living and stability of civil society. The last two decades are characterized by a favorable dynamics of infant mortality in the cities, which was caused primarily by the improving well-being of the Bulgarians. However, infant mortality in the country remains almost twice as high (6.7\%o) as the average for the European Union.

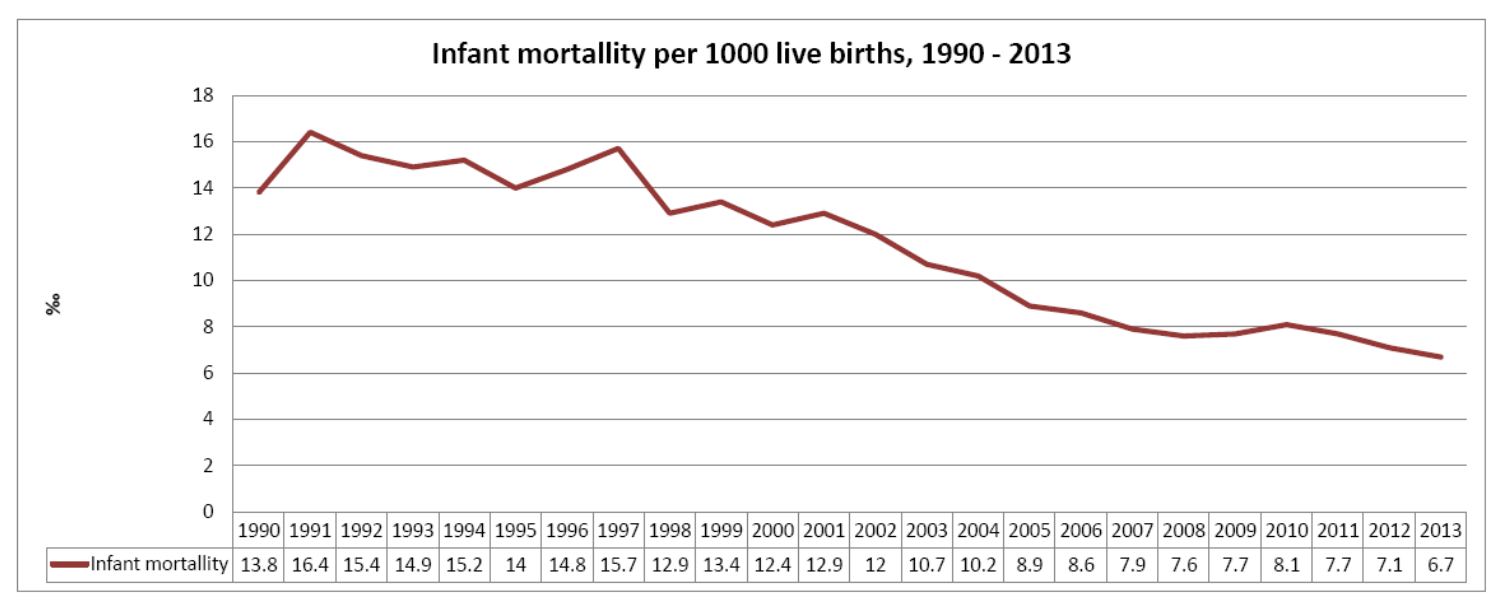

Figure 6, Source: National Statistical Institute

Natural growth of the urban population is characterized by negative values (from - $3.7 \%$ o to $-0.7 \%$ ). An exception is the beginning of the period when values are positive. Rate of population growth in cities is - $2.8 \%$, and in villages - $11.8 \%$. The negative demographic trends in the villages are the main reason for the noted decrease in population in Bulgaria as a result of natural growth. 


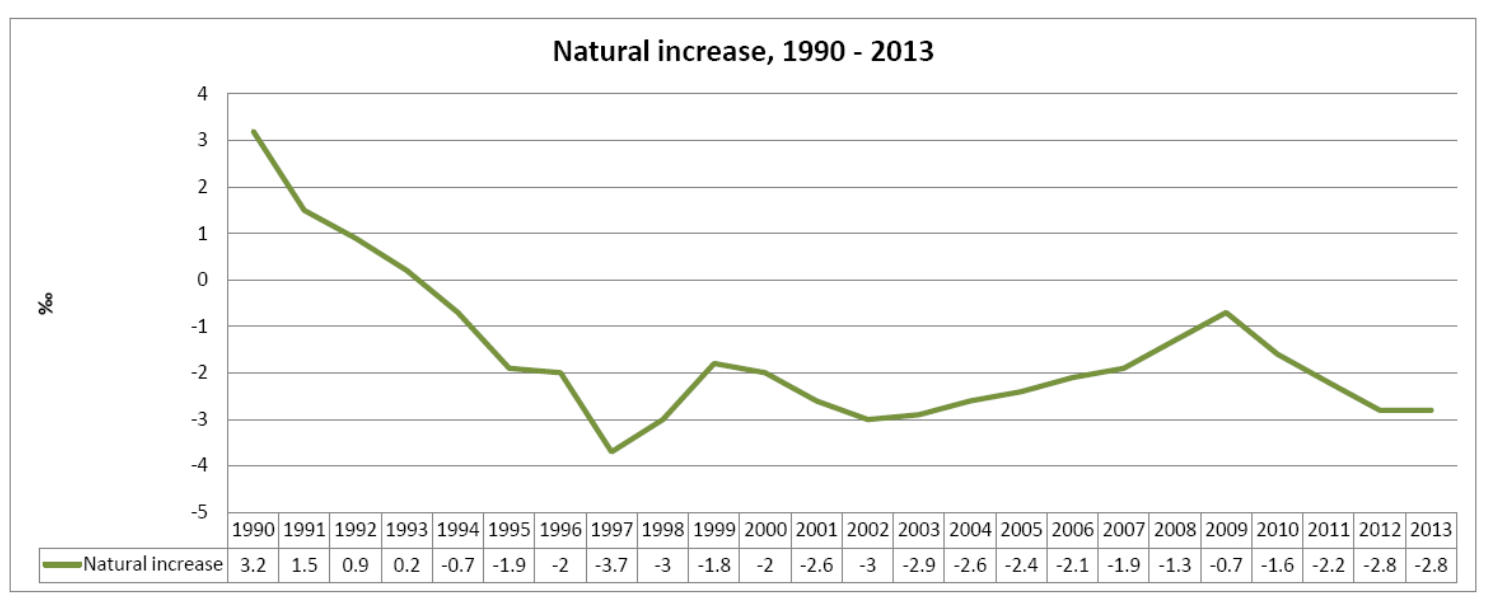

Figure 7, Source: National Statistical Institute

The nature of the migration situation in Bulgaria is changed by the democratic changes in the country and the eastern enlargement of the European Union. It is also due to the economic and cultural globalization worldwide. Unlike the period before 1989, when Bulgaria had a very limited migration profile after the democratic changes she is a full participant in the migration processes of European and global level. Bulgaria is no exception to the global trends of increased mobility of the population due to the rapid development of technology, accessible transport and communications.[2] In 2013 in the migration between the different settlements in the country were involved 86,378 persons. The mass migration flows $(45.5 \%)$ are from city to city. Significantly smaller are the migration flows under the "village - village" (9.4\%). The share of the population, which migrated from towns to rural areas $(23.5 \%)$ is higher than in the reverse direction "village - city" (21.6\%). As a result of the migration between urban and rural areas, the population in the cities decreased (respectively the rural population increased) by 1617 people.

We can conclude that the trend of increasing the share of urban population and reduce rural population remains. Relatively rapid aging of the population in the cities of Bulgaria requires vigorous economic, institutional, administrative, budgetary and financial developments, the luck of which will be impaired cohesion in society, solidarity between generations and will have new, intractable problems for future generations. In demographic terms aging is irreversible. The answer to this challenge must be directed to the mechanical change in the basic demographic indicators and to the implementation and development of integrated population policy. It is necessary to mobilize and make full use of the possibilities of the human resources available and targeted investment in improving the quality of human capital. The measures set out in the demographic policy in terms of their influence can be seen as stimulating or restricting. As a rule, however, the incentives and constraints influence the behavior limited time and people adapt to them and not perceive them as such.[3] The most important part of the policy measures is those that are located in the so-called. "Golden mean" (between stimulus and restraint). We call them "Social guarantors for demographic development of cities" They provide stability and predictability of the conditions in which people realize their demographic needs. 


\section{REFERENCES}

[1] Minkov, M. Demography, Bulgaria, Sofia, 1999.

[2] National Strategy of the Republic of Bulgaria for Migration and Integration, Bulgaria, Sofia, $2008-2015$

[3] Naydenov, Kl. Demographic policy of the Republic of Bulgaria - a factor for sustainable development. Dissertation for awarding the educational and scientific degree "doctor", Bulgaria, Sofia, 2012.

[4] Updated National Strategy for Demographic Development of the Republic of Bulgaria (2012-2030). Bulgaria, Sofia, 2012 